\title{
Editorial
}

\section{Sustainable Use of Nature-Based Solutions for Slope Protection and Erosion Control}

\author{
Alejandro Gonzalez-Ollauri (B)
}

Citation: Gonzalez-Ollauri, A. Sustainable Use of Nature-Based Solutions for Slope Protection and Erosion Control. Sustainability 2022 14, 1981. https://doi.org/10.3390/ su14041981

Received: 3 February 2022 Accepted: 7 February 2022 Published: 9 February 2022

Publisher's Note: MDPI stays neutral with regard to jurisdictional claims in published maps and institutional affiliations.

Copyright: (C) 2022 by the author. Licensee MDPI, Basel, Switzerland This article is an open access article distributed under the terms and conditions of the Creative Commons Attribution (CC BY) license (https:// creativecommons.org/licenses/by/ $4.0 /)$.
The BEAM Research Centre, School of Computing, Engineering and Built Environment, Glasgow Caledonian University, Glasgow G4 0BA, UK; alejandro.ollauri@gcu.ac.uk

Soil loss is a global threat to the integrity and function of the Earth's ecosystems. Soil loss can have dramatic implications for the provision of essential food and resources to human communities. Soil loss and degradation can be accelerated by landslides and erosion, which are two ubiquitous natural hazards. These hazards are commonly triggered by rainfall, which impacts on soil structure and its mechanical integrity. Consequently, the severity and recurrence of landslides and erosion will likely increase due to the intensification of the hydrological cycle predicted under the scenarios of climate change, leading to further soil loss and degradation. It is becoming evident that we are currently experiencing a climate crisis and emergency in our planet, so we must not only take action against climate change, but also against its tangible effects on our environment. This a unique opportunity to learn from nature and understand how it functions, so we can find sustainable solutions to the challenges ahead, such as the intensification of landslides and erosion, and so we can help human communities become resilient to climate change.

Nature-based solutions (NBSs) can be understood as ecology-based, integrated approaches that work alongside nature to manage natural hazards, address societal challenges, and solve engineering problems sustainably whilst providing co-benefits and ecosystem services to human communities. The concept of NBS is relatively easy to understand by the layperson, as the word is self-explanatory-i.e., those actions striving to find solutions to problems by using natural elements and processes. However, there is no official consensus on how NBSs must be defined. The concept of NBSs can be regarded as an umbrella term under which multiple disciplines can be found, such as ecosystem-based approaches (to climate adaptation), natural systems agriculture, natural solutions, green infrastructure and/or ecological engineering, etc. In fact, the combination of NBS approaches may lead to the obtainment of better results when an environmental challenge must be addressed.

The management and mitigation of natural hazards such as landslides and erosion necessitate strategies that bridge engineering principles with ecosystem functioning and, in most cases, with sensible approaches to land management. Multiple examples of ecologybased, integrated approaches employed to address landslides, erosion, and even flooding can be found within the disciplines of soil and water bioengineering. Soil and water bioengineering often use techniques that combine landscape architecture, soil mechanics, hydrology, plant ecology, and now, ecosystem services management. These techniques can be regarded as plant-based NBSs, as vegetation is a key structural and functional element of a given NBS intervention. Vegetation thus ensures the sustainability, performance, resilience, and integration within the local environment of NBS interventions. Researchers and practitioners working on NBSs should take a close look at the examples provided by soil and water bioengineering to gain insights into how NBSs must be defined in a context of mitigating and managing hazards related to climate change. In fact, one of the main challenges currently faced by NBSs, which is the lack of a solid evidence base related to their performance, could somehow be circumvented by looking into other disciplines that have employed NBSs even before the term was coined, such as soil and water bioengineering. 
The lack of evidence on how NBSs perform has been identified as the greatest limitation to encouraging their uptake and upscaling. NBSs will only make a difference in the battle against climate change if they are used globally and at a large scale. A sound evidence base on NBS performance does not exist yet because there are no established frameworks, protocols, standards, and indicators to quantify it [1] and which can be used with confidence by scientists and practitioners alike. More importantly, the lack of evidence may have a negative impact on the perception of NBSs by the public, who may thus favour more traditional approaches, such as those coined as 'grey' or 'hybrid', overlooking the many co-benefits and ecosystem services that NBSs can provide. Consequently, research and studies that can contribute to filling the knowledge gap of how NBSs perform should be particularly welcome by the scientific community, policy and decision makers, and by the public in general. New insights into NBS performance will undoubtedly encourage and facilitate the inclusion of NBS design within risk reduction strategies and push business exploitation.

This Special Issue (SI) aimed to gather a series of original contributions including, but not limited to, novel research, tools, frameworks, approaches, indicators, and case studies focusing on examples demonstrating how NBSs can be used sustainably for erosion control and slope protection. In total, nine contributions were submitted to the SI. These contributions came from multiple European countries in addition to one case study focusing on South America, suggesting that efforts to understand and utilise NBSs against landslides and erosion cross borders and continents. Yet, it also indicates that further work is needed to contribute towards a global evidence base on how NBSs perform. What follows is a brief overview of the nine interesting contributions to the SI entitled "Sustainable use of Nature-based Solutions for slope protection and erosion control". I hope that this overview will encourage the reader to explore the contents of the SI in more depth.

Apollonio et al. [2] provided an original approach to set up onsite experiments and measure erosion rates under multiple rainfall events and ground covers. A related study was carried out by Stanchi et al. [3] who looked into the effect of soil management on erosion in mountain vineyards. These authors provided further evidence on how sensible approaches to land management, in this case agricultural land, can substantially help to reduce erosion and therefore soil loss and degradation. In addition to assessing the impact of vegetation on soil reinforcement to address erosion and landslide hazards, Capobianco et al. [4], used a novel, numerical modelling approach to assess the hydro-mechanical effect of several riparian vegetation combinations on streambank stability in Norway. The latter study focused on the key element of NBSs against landslides and erosion. In this particular case, they focused on woody vegetation and on providing a numerical modelling tool to quantify the ability of NBSs to manage the stability of streambanks, which is very much related to the virulence of flooding events.

In relation to the former study, Gonzalez-Ollauri and Mickovski [5] provided an approach supplemented with primary evidence that demonstrated the hydrological effect of willow on soil-water dynamics. This is key to understanding how vegetation and hence NBSs can contribute to managing and mitigating shallow landslides. It is worth noting that willow is a common species used in soil bioengineering for its ability to resprout from cuttings, but also due to its great resilience to waterlogged conditions and soil pollution. In this regard, Sorolla et al. [6] explored how vegetation was established in NBS interventions designed for slope stability. In particular, the authors explored how different planting strategies can help vegetation establish on vegetated cribwalls, which is a common NBS technique in soil and water bioengineering. The findings from these authors will surely contribute to enhancement of the successful use of cribwalls against landslides and erosion. More examples regarding soil and water bioengineering techniques are discussed in Maxwald et al. [7], who showcased multiple case studies implemented in South America and proposed an original framework helping to make these NBS interventions transferable to other sites. The latter is of the utmost importance to ensure NBSs can be replicated and upscaled. Yet, scientists and practitioners working with NBSs also need to deliver a sound evidence base on NBS performance, and for which monitoring is essential. In 
this regard, Koutalakis et al. [8] shared insights into how UAV (unmanned aerial vehicle) technology can be used to monitor hazards in the context of NBSs. The protocols these authors discussed in their study can help investigate the evolution of NBSs in the landscape but can also help understand how NBSs and landscape interventions contribute to the management of landslides. The Special Issue concludes with two interesting opinion and perspective articles written by two well-established soil bioengineers. Rey [9] discussed the harmonisation of erosion control and flood prevention with the restoration of biodiversity through ecological engineering approaches. Mickovski [10] took this topic further and provided an original, thought-provoking discussion on how soil bioengineering can address climate change challenges.

Funding: This research received no external funding.

Institutional Review Board Statement: Not applicable.

Informed Consent Statement: Not applicable.

Data Availability Statement: Not applicable.

Conflicts of Interest: The author declares no conflict of interest.

\section{References}

1. Gonzalez-Ollauri, A.; Munro, K.; Mickovski, S.B.; Thomson, C.S.; Emmanuel, R. The 'Rocket Framework': A Novel Framework to Define Key Performance Indicators for Nature-based Solutions Against Shallow Landslides and Erosion. Front. Earth Sci. 2021, 9 , 1018. [CrossRef]

2. Apollonio, C.; Petroselli, A.; Tauro, F.; Cecconi, M.; Biscarini, C.; Zarotti, C.; Grimaldi, S. Hillslope Erosion Mitigation: An Experimental Proof of a Nature-Based Solution. Sustainability 2021, 13, 6058. [CrossRef]

3. Stanchi, S.; Zecca, O.; Hudek, C.; Pintaldi, E.; Viglietti, D.; D'Amico, M.E.; Colombo, N.; Goslino, D.; Letey, M.; Freppaz, M. Effect of Soil Management on Erosion in Mountain Vineyards (N-W Italy). Sustainability 2021, 13, 1991. [CrossRef]

4. Capobianco, V.; Robinson, K.; Kalsnes, B.; Ekeheien, C.; Høydal, Ø. Hydro-Mechanical Effects of Several Riparian Vegetation Combinations on the Streambank Stability-A Benchmark Case in Southeastern Norway. Sustainability 2021, 13, 4046. [CrossRef]

5. Gonzalez-Ollauri, A.; Mickovski, S. The Effect of Willow (Salix sp.) on Soil Moisture and Matric Suction at a Slope Scale. Sustainability 2020, 12, 9789. [CrossRef]

6. Sorolla, A.; Piera, E.; Mota-Freixas, B.; Salvans, G.S.; Rueda, I.; Prats, A.L.; Unzeta, C. Improvement of the Plantation Success in a Crib Wall in a Mediterranean Hydro-Meteorological Risks Scenario-Practical Results. Sustainability 2021, 13, 11785. [CrossRef]

7. Maxwald, M.; Crocetti, C.; Ferrari, R.; Petrone, A.; Rauch, H.; Preti, F. Soil and Water Bioengineering Applications in Central and South America: A Transferability Analysis. Sustainability 2020, 12, 10505. [CrossRef]

8. Koutalakis, P.; Tzoraki, O.; Prazioutis, G.; Gkiatas, G.; Zaimes, G. Can Drones Map Earth Cracks? Landslide Measurements in North Greece Using UAV Photogrammetry for Nature-Based Solutions. Sustainability 2021, 13, 4697. [CrossRef]

9. Rey, F. Harmonizing Erosion Control and Flood Prevention with Restoration of Biodiversity through Ecological Engineering Used for Co-Benefits Nature-Based Solutions. Sustainability 2021, 13, 11150. [CrossRef]

10. Mickovski, S. Re-Thinking Soil Bioengineering to Address Climate Change Challenges. Sustainability 2021, 13, 3338. [CrossRef]

\section{Short Biography of Author}

Alejandro Gonzalez-Ollauri is a determined multidisciplinary researcher who feels passionate for Nature and takes joy in learning. His research interests focus on plant-soil-atmosphere interactions, soil bioengineering, Nature-based Solutions against natural hazards, and the development of simple numerical tools to answer complex environmental questions. Alejandro obtained a 1st Class BSc in Environmental Science with Honours at the University of Salamanca, Spain, in 2006. He then secured an RA position to work in a project looking at the sustainable nutrition of tree crops within the Valencian Institute for Agricultural Research. While working as RA, he obtained a 1st Class, BEng in Agricultrual Engineering in 2010. Alejandro was then granted a scholarship to undertake an Erasmus Mundus MSc in Applied Ecology. Moving between the universities of Poitiers (France), East Anglia (UK), Coimbra (Portugal), and Kiel (Germany), Alejandro became a resourceful researcher. In 2013, he was awarded with a PhD studenship at GCU, where he has been working since on the mitigation of natural hazards, such as landslides or soil pollution, using vegetation. Alejandro completed successfully his docotoral studies within 3 years. He currently holds a Research Fellow position at the BEAM Research Centre, teaches Hydrology and GIS to BSc and MSc students, demonstrates in Soil Mechanics to BEng students, collaborates in several international research projects, and enjoys reviewing and editing for high-rank scientific journals. 